\title{
Ouabain-induced alterations in ABCB1 of mesenteric lymph nodes and thymocytes of rats and mice
}

\author{
DANIEL BOFF LIMA ${ }^{1}$, RAPHAEL CARMO VALENTE ${ }^{2}$ and MARCIA ALVES MARQUES CAPELLA ${ }^{1,2}$ \\ ${ }^{1}$ Institute of Medical Biochemistry Leopoldo de Meis; ${ }^{2}$ Institute of Biophysics Carlos Chagas Filho, \\ Federal University of Rio de Janeiro, Rio de Janeiro, RJ 21949-900, Brazil
}

Received February 7, 2016; Accepted June 27, 2016

DOI: $10.3892 / \mathrm{ol} .2016 .5366$

\begin{abstract}
Ouabain is a glycoside with immunomodulating properties, and recent studies have suggested its use in adjuvant therapy for cancer treatment. Ouabain is known to modulate the immune system in vitro, and previous studies have revealed that ouabain can modulate the expression and activity of ABCB1, a protein associated with multidrug resistance present in immune system. Therefore, the present study investigated alterations in the expression and activity of $\mathrm{ABCB} 1$ in the thymi, peripheral blood monocytes and lymph nodes of Wistar rats and Swiss mice treated acutely or chronically with ouabain. A decrease of almost $45 \%$ in the monocyte count and an increase of $55 \%$ in the basophil count were observed. A significant decrease (75\% reduction) in the amount of cells with ABCB1 activity was found in the thymocytes of ouabain-treated rats and mice. The possible implications of these results for cancer treatment are discussed.
\end{abstract}

\section{Introduction}

Since its discovery as a $\mathrm{Na} / \mathrm{K}$-adenosine triphosphatase (ATPase) inhibitor, ouabain has been an important topic of research in virtually all aspects of biochemistry, biophysics and physiology. A number of studies revealed the existence of an endogenous analog of ouabain in the plasma and certain mammalian tissues, including human tissues (1-3), and increased levels of this hormone are associated with hypertension (4). Furthermore, prolonged infusion of ouabain in animal models induces significant increases in blood pressure $(5,6)$; although the mechanisms underlying the association between the onset of hypertension and enhanced levels of plasma ouabain remain unknown.

Correspondence to: Dr Marcia Alves Marques Capella, Institute of Biophysics Carlos Chagas Filho, Federal University of Rio de Janeiro, 373 Carlos Chagas Filho Avenue, Block C, University City, Island of Fundão, Rio de Janeiro, RJ 21949-900, Brazil E-mail: mcapella@biof.ufrj.br

Key words: ouabain, ATP binding cassette subfamily B member 1, immune system, cancer, rat, mouse
Previously, several studies suggested an anticancer role for ouabain, which appears to be involved in complex cell-signal transduction mechanisms that result in the selective control of tumor growth (7-10). In contrast to the promising use of ouabain in tumor growth control, studies have shown that ouabain can increase the expression of ATP binding cassette subfamily B member 1 (ABCB1) $(11,12)$. ABCB1, also known as $\mathrm{P}$-glycoprotein, confers resistance to several unassociated drugs, and is therefore a major concern in cancer chemotherapy $(11,13)$. One approach to circumvent this resistance may be to inhibit the activity of ABCB1. However, due to the important physiological actions of $\mathrm{ABCB} 1$ that affect several organs and tissues, including cells from the immune system, this approach is clearly not a reasonable alternative (13).

Cancer is a multifactorial disease, and cancer patients often show alterations in the immune system (14). Ouabain is known to interfere with this system (15), and ABCB1 is a protein directly associated with several functions of the immune system (16-19). At present, few studies have examined the effects of ouabain on ABCB1 expression and activity in the immune system in vivo. Therefore, the aim of the present study was to assess the in vivo effects of ouabain on immune cell counts in the blood and on ABCB1 activity in the thymus, peripheral blood mononuclear cells and mesenteric lymph nodes in order to contribute to the possible use of this glycoside in cancer therapy.

\section{Materials and methods}

Animal preparation. All animal procedures were previously reviewed and approved by the Animal Subject Committee of the UFRJ Health Science Centre (Rio de Janeiro, Brazil; protocol nos. IBCCF 082/2009 and 153/13). Male Wistar rats weighing between 260-280 $\mathrm{g}$ and male Swiss mice weighing between 26-32 g received food and water ad libitum.

\section{Treatment with ouabain}

Wistar rats. Male Wistar rats were treated with daily intraperitoneal injections of $30 \mu \mathrm{g} / \mathrm{kg}$ of ouabain (Sigma-Aldrich, St. Louis, MO, USA) or its vehicle, phosphate-buffered saline (PBS). A total of 20 rats were used, 12 for acute treatment ( $n=6$ rats/group in ouabain and control groups) and 8 for chronic treatment $(n=4$ rats/group in ouabain and control groups). Animals were maintained under standard laboratory 
conditions, with room temperature controlled $\left(22^{\circ} \mathrm{C}\right)$, and subjected to $12 \mathrm{~h}$ light-dark cycles with ad libitum access to food and water. Prior to the first injection at $24 \mathrm{~h}$ and 7 and 14 days subsequent to the injection, the rats had their blood pressure measured by a computerized tail-cuff method. The animals were sacrificed by barbiturate overdose $(86 \mathrm{mg} / \mathrm{kg}$ intraperitoneal injection of pentobarbital) after $24 \mathrm{~h}$ (acute treatment) or 14 days (chronic treatment) of ouabain injections, and the mesenteric lymph nodes, thymi and blood were collected. Full excisions of thymi and partial excisions of mesentheric lymph nodes were performed, while blood samples were collected by caudal venous puncture prior to animals sacrifice.

Mesenteric lymph nodes and thymi were softly dissociated, and the remaining cells were washed in PBS and centrifuged at $200 \mathrm{x}$ g. The pellet was suspended in ice-cold RPMI-1640 medium (Sigma-Aldrich) supplemented with 10\% fetal bovine serum (FBS; Gibco; Thermo Fisher Scientific, Inc., Waltham, MA, USA). Heparinized blood (200 $\mu \mathrm{l})$ was separated for an evaluation of hematological parameters, and $5 \mathrm{ml}$ was centrifuged on a Ficoll-Hystopaque (Sigma-Aldrich) density gradient at $200 \mathrm{x} \mathrm{g}$ to isolate the peripheral blood mononuclear cells (PBMC). The sample was then resuspended in the same culture medium and stored on ice until required for the activity assays.

Swiss mice. A total of 8 mice were used in the present study, 4 in the control group and 4 in the ouabain-treated group. Animals were maintained under standard laboratory conditions, with room temperature controlled $\left(22^{\circ} \mathrm{C}\right)$, and subjected to $12 \mathrm{~h}$ light-dark cycles with ad libitum access to food and water. At $24 \mathrm{~h}$ subsequent to the intraperitoneal injection with $300 \mu \mathrm{g} / \mathrm{kg}$ of ouabain or PBS, the Swiss mice were sacrificed by barbiturate overdose $(86 \mathrm{mg} / \mathrm{kg}$ intraperitoneal injection of pentobarbital). The mesenteric lymph nodes and thymi were immediately removed and softly dissociated. The remaining cells were washed in PBS and centrifuged at $200 \mathrm{x}$ g. The pellet was suspended in ice-cold RPMI-1640 culture medium supplemented with $10 \%$ FBS until required for the activity assays.

Blood pressure measurement. Mean blood pressure was recorded in conscious, resting Wistar rats by a non-invasive oscillometric tail-cuff method (LE5001 Pressure Meter; Letica SA, Barcelona, Spain). One week prior to the initiation of the experiments, the rats were accustomed to restraint and inflation of the tail cuff in two independent sessions, to minimize non-specific stress. All measures were recorded in the morning, between 9 and $11 \mathrm{am}$. For each session, at least 7 blood pressure readings were recorded.

Activity assay by flow cytometry. Rhodamine (Rho) 123 (Sigma-Aldrich) was used to measure ABCB1 activity in lymphocytes from PBMCs, mesenteric lymph nodes and in thymocytes, as previously described (20). The gates used to select the lymphocytes from PBMC, mesenteric lymph nodes and thymocytes were performed using forward and side scattering, according to previous descriptions $(21,22)$.

Statistical analysis. Each experiment was performed with at least 4 animals in each group. Data are expressed as the mean \pm standard error of the mean and were analyzed using
Table I. White blood cell count of Wistar rats acutely treated with ouabain.

\begin{tabular}{lrr}
\hline Cells & \multicolumn{1}{c}{ Control } & \multicolumn{1}{c}{ Ouabain } \\
\hline Leukocytes, $\times 10^{3} / \mu 1$ & $3.18 \pm 0.20$ & $3.60 \pm 0.39$ \\
Basophils, \% & $1.55 \pm 0.23$ & $2.41 \pm 0.23^{\mathrm{a}}$ \\
Eosinophils, \% & $2.34 \pm 0.26$ & $2.25 \pm 0.32$ \\
Neutrophils, \% & $21.90 \pm 2.08$ & $18.75 \pm 3.28$ \\
Lymphocytes, \% & $73.22 \pm 2.16$ & $76.05 \pm 3.61$ \\
Monocytes, \% & $0.99 \pm 0.19$ & $0.54 \pm 0.15^{\mathrm{b}}$ \\
\hline
\end{tabular}

${ }^{\mathrm{a}} \mathrm{P}=0.027,{ }^{\mathrm{b}} \mathrm{P}=0.048$, unpaired Student's $t$-test.

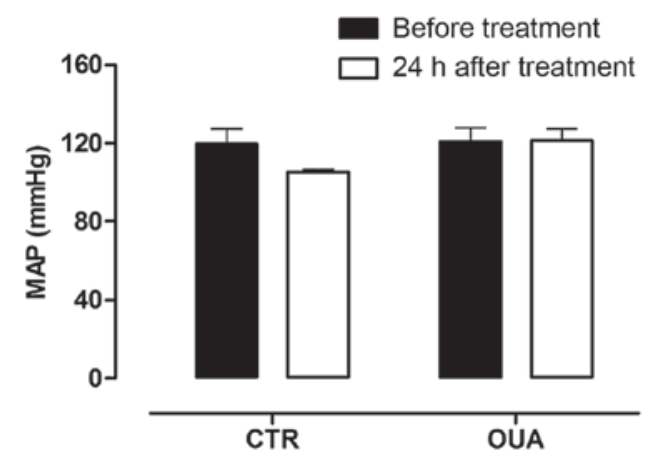

Figure 1. MAP of Wistar rats following acute treatment with ouabain. Values obtained before (full bars) and $24 \mathrm{~h}$ after (empty bars) the injection of $30 \mu \mathrm{g} / \mathrm{kg}$ of ouabain. Data are expressed as the mean \pm standard error of the mean, using two-way analysis of variance $(n=4)$. MAP, mean arterial pressure; CTR, control; OUA, ouabain.

two-way analysis of variance (blood pressure analyses) or an unpaired Student's $t$-test. Values of $\mathrm{P}<0.05$ were considered to indicate a statistically significant difference.

\section{Results}

Acute ouabain treatment. As expected, the mean arterial pressure (MAP) of Wistar rats injected with a single dose of ouabain was similar to the MAP obtained prior to the administration of either ouabain or PBS (prior to injection, $121 \pm 7 \mathrm{mmHg} ; 24 \mathrm{~h}$ following intraperitoneal ouabain injection, $122 \pm 6 \mathrm{mmHg}$ ) (Fig. 1). However, significant alterations were identified in the basophil and monocyte populations, with basophil populations being increased by 55\% and monocyte populations being decreased by almost $45 \%$ in blood samples from animals treated with ouabain (Table I). No alterations in red cells characteristics were observed (data not shown).

Ouabain has been shown to induce alterations in the expression and activity of $\mathrm{ABCB} 1$ in vitro $(11,12)$. Therefore, the present study tested whether a single in vivo administration of ouabain could result in alterations in $\mathrm{ABCB} 1$ protein expression in lymph nodes and thymi. ABCB1 activity is only observed in $5-10 \%$ of thymocytes, as it is restricted to the most immature subset, the double negative cluster of differentiation (CD) $4 \%$ CD 8 - subpopulation, and to the fully mature subset, the $\mathrm{CD}^{+}$and $\mathrm{CD}^{+} \mathrm{T}$ cells (23). Therefore, the number of cells 

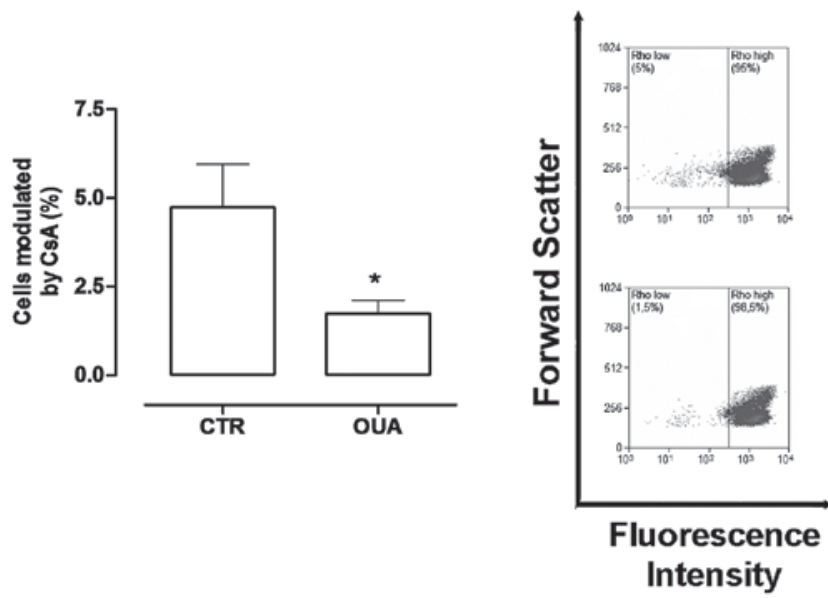

Figure 2. Modulation of ABCB1 activity in thymocytes of Wistar rats acutely treated with $30 \mu \mathrm{g} / \mathrm{kg}$ of ouabain. (A) Each bar represents the difference between extrusions with Rho123+CsA and Rho123 alone in the Rho low region, $24 \mathrm{~h}$ after the injection of ouabain. Data are expressed as the mean \pm standard error of the mean, using the Student's unpaired $t$-test ${ }^{*} \mathrm{P}=0.041$ ( $\left.\mathrm{n}=6\right)$. (B) Representative experiment showing Rho low region, where cells poorly accumulate Rho123, indicating ABCB1 activity. Dot plots represent extrusions in the absence (upper panel) or presence (lower panel) of CsA. ABCB1, ATP binding cassette subfamily B member 1 Rho, rhodamine: CsA, cyclosporin A; CTR, control; OUA, ouabain.

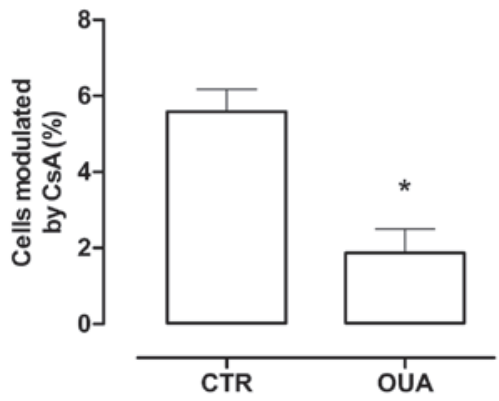

Figure 3. Modulation of ABCB1 activity in thymocytes of Swiss mice acutely treated with ouabain. Data are expressed as the mean \pm standard error of the mean, using the Student's unpaired $t$-test. " $\mathrm{P}=0.028(\mathrm{n}=5)$. CsA, cyclosporin A; CTR, control; OUA, ouabain; ABCB1, ATP binding cassette subfamily B member 1.

presenting $\mathrm{ABCB} 1$ activity in the thymus was determined by the percentage of cells with low Rho content, which were modulated by the ABCB1 inhibitor cyclosporin A (CsA) (Fig. 2A). However, as the majority of mature lymphocytes demonstrate $\mathrm{ABCB} 1$ activity, the gates used to analyze the percentage of cells modulated by CsA were drawn by dividing the population into two halves, using the incubation with Rho123 as a reference (Fig. 2B).

Fig. 2A shows that the percentage of thymocytes with ABCB1 activity in control rats was almost 5\%, which was obtained by corroborating previous results (23); however, in the thymocytes of rats pretreated with ouabain, this activity decreased by $\sim 50 \%$ of the control. Treatment with ouabain did not alter the number of cells modulated with CSA in PBMCs or mesenteric lymph nodes (data not shown).

To evaluate whether the observed effect in thymocytes was species dependent, the same experiments were performed in mice. Due to the difficulties in obtaining and separating blood

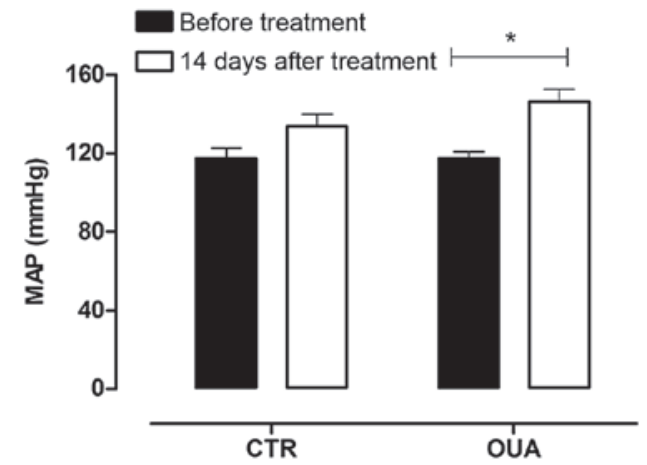

Figure 4. MAP of Wistar rats following chronic treatment with ouabain. Values obtained before (full bars) and 14 days after (empty bars) the injection of $30 \mu \mathrm{g} / \mathrm{Kg}$ of ouabain. Data are expressed as the mean \pm standard error of the mean, using two-way analysis of variance. ${ }^{*} \mathrm{P}=0.004(\mathrm{n}=4)$. MAP, mean arterial pressure; CTR, control; OUA, ouabain.

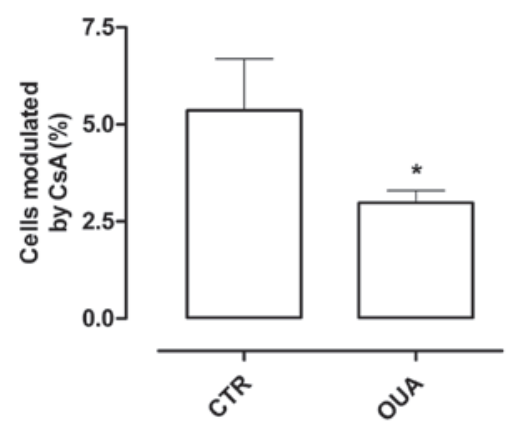

Figure 5. Modulation of ABCB1 activity in thymocytes of Wistar rats chronically treated with ouabain. Data are expressed as the mean \pm standard error of the mean, using the Student's unpaired $t$-test. ${ }^{*} \mathrm{P}<0.05(\mathrm{n}=4)$. CsA, cyclosporin A; CTR, control; OUA, ouabain; ABCB1, ATP binding cassette subfamily B member 1 .

cells from the mice, only lymph nodes and thymi were tested. As shown in Fig. 3, the same results were obtained, with an approximate $50 \%$ reduction of $\mathrm{ABCB} 1$ activity in the thymi and no difference in lymph nodes.

Chronic ouabain treatment. Since a chronic treatment with ouabain may lead to hypertension and, to the best of our knowledge, no studies assess ABCB1 activity in chronic ouabain-treated animals, the present study also tested the effects of chronic ouabain treatment on ABCB1 activity in the lymph nodes and thymi of rats. The rats were treated daily with intraperitoneal injections of $30 \mathrm{mg} / \mathrm{kg}$ ouabain. The MAP was measured on days 0,7 and 14. As shown in Fig. 4, after 14 days the MAP of ouabain-treated rats was significantly elevated. The animals were then sacrificed and the ABCB1 activity was measured. Fig. 5 shows that the effect observed in the thymus with acute ouabain treatment remained present following chronic treatment. In addition, the ABCB1 activity of mesenteric lymph nodes was also diminished after chronic treatment with ouabain.

\section{Discussion}

To the best of our knowledge, the present study is the first to evaluate the effects of acute ouabain treatment in the blood. The 
dose of ouabain used (30 $\mu \mathrm{g} / \mathrm{kg})$ has been previously shown to induce hypertension when infused or released subcutaneously for long periods of time in Wistar rats $(6,24)$. Corroborating with the results of other studies $(6,24)$, the current study found that ouabain increased the MAP after 14 days of continuous daily treatment, but did not promote any alteration in the blood pressure of Wistar rats after $24 \mathrm{~h}$. However, the acute administration of ouabain was found to induce significant alterations to the basophil and monocyte counts in the peripheral blood.

Basophils are granulocytes known to participate in allergic reactions and parasite infections. This type of cell expresses major histocompatibility complex class II, CD80 and CD86, and has the potential to capture and process antigens and present peptides to effector cells, which promote the development of Thelper 2 cells via early secretion of interleukin (IL)- 4 during allergic immune responses (25). The differentiation of bone marrow precursors in basophils requires IL-3, and these differentiated cells are capable of producing histamine, IL-4, IL-13 and leukotriene C4 (26), which is an important substrate described for another member of the ABC superfamily, ABCC1 (27). Basophilia has a strong association with certain malignancies, particularly acute and chronic myeloid leukemia (26).

Monocytes are mononuclear cells present in the blood, which, after activation, migrate from the blood to the tissues and usually differentiate into macrophages. Monocytes are important for the initiation, amplification and shutdown of the immune response through the production of cytokines, recognition of pathogen-associated molecular patterns, antigen presentation and phagocytosis (28-30). Ebner et al (31) demonstrated that monocytes can differentiate in dendritic cells after stimulation with IL-3 and IL-4.

The actions of ouabain are extremely diverse and may vary according to the target organ or tissue. Certain studies have shown important implications of the ouabain hormone in cell proliferation, muscle contraction and cell survival in distinct cell types (32-34). In the immune system, ouabain modulates the expression of several important receptors in lymphocytes and monocytes $(35,36)$, impairs lymphocyte proliferation induced by mitogens (36) and induces cytokine secretion in PBMC $(37,38)$. In addition, the in vivo administration of ouabain has been shown to reduce the amount of mature B lymphocytes in the spleen and prevent the inflammation induced by several substances in mice $(39,40)$.

Although no studies make direct associations between ouabain and IL-3, certain studies have shown that ouabain interferes with other interleukin pathways $(41,42)$ and that IL-3 activates $\mathrm{Na}^{+} / \mathrm{K}^{+}$-ATPase, which is the main target of ouabain, in macrophages (43). Therefore, the possibility that ouabain regulates the synthesis or secretion of IL-3, which could result in augmented number of basophils and reduced number of monocytes in peripheral circulation, cannot be ruled out. In addition, it has been reported that ouabain affects the activation of monocytes and modulates their functions, acting as an immunomodulator of these cells (44).

At present, the consequences of the observed alterations in leukocyte counts that were induced by short-term treatment with ouabain remain unclear; however, these alterations could potentially affect the immune response of cancer patients. Since basophilia has been shown to be associated with a bad prognosis (reduced survival) in myelodysplastic syndromes (45) and also in patients with solid tumors (46), the present observations suggest that additional studies are required to assess the use of ouabain for treatment in cancer patients.

Ouabain is known to modulate the expression of two ATPases associated with cancer resistance, ABCB1 and ABCC1 (47). Therefore, the present study aimed to assess whether ouabain could alter the expression or activity of $\mathrm{ABCB} 1$ in PBMC and thymocytes in vivo. Indeed, acute and chronically ouabain-treated Wistar rats displayed significant decrease in $\mathrm{ABCB} 1$ activity in lymphocytes from the thymus. Despite being more resistant to ouabain compared with rats (48), which explains the greater dose $(300 \mu \mathrm{g} / \mathrm{kg})$ used, Swiss mice acutely treated with the ABCB1 glycoside also presented similar results, indicating that this effect is not species-dependent.

ABCB1 is associated with the transport of several substrates, including lipids, hormones and cytokines $(19,49,50)$. In thymocytes, the expression of this protein is restricted to the double negative (CD4/CD8 ${ }^{-}$) thymocytes and to the simple positive populations $\mathrm{CD} 4^{+}$and $\mathrm{CD}^{+}$, representing the most immature subset and the mature thymocyte populations, respectively (23). Thus, the observation that ouabain induced a significant decrease in the percentage of thymocytes with ABCB1 activity raises at least three hypotheses: i) That thymocytes with $\mathrm{ABCB} 1$ are simply undergoing protein downregulation in the plasma membrane; ii) that thymocyte maturation is being impaired, leading to an accumulation of double positive cells $\left(\mathrm{CD} 4^{+} / \mathrm{CD}^{+}\right)$, which do not exhibit ABCB1 activity; or iii) that the thymocytes with decreased ABCB1 activity after the ouabain injection could be undergoing apoptosis. Although, at present, the significance of the present observations is not understood, the findings suggest that ouabain could contribute to immunodeficiencies in cancer patients, which argues against its use in cancer treatment.

As the immune system is directly associated with the development of cancer, and since acute and chronic treatment with ouabain were able to alter the activity of ABCB1 in immature lymphocytes and the percentage of monocytes and basophils in the peripheral blood, the current results suggest that additional studies are required to assess the use of ouabain as an adjuvant anticancer therapy, and may also contribute to elucidating the mechanisms of development of hypertension triggered by ouabain.

\section{Acknowledgements}

The present study was supported by grants from the Cancer Foundation (Rio de Janeiro, Brazil) and the National Council for Scientific and Technological Development (Brasília, Brazil).

\section{References}

1. Tymiak AA, Norman JA, Bolgar M, DiDonato GC, Lee H, Parker WL, Lo LC, Berova N, Nakanishi K and Haber E: Physicochemical characterization of a ouabain isomer isolated from bovine hypothalamus. Proc Natl Acad Sci USA 90: 8189-8193, 1993.

2. Ludens JH, Clark MA, Robinson FG and DuCharme DW: Rat adrenal cortex is a source of a circulating ouabainlike compound. Hypertension 19: 721-724, 1992. 
3. Hamlyn JM, Blaustein MP, Bova S, DuCharme DW, Harris DW, Mandel F, Mathews WR and Ludens JH: Identification and characterization of a ouabain-like compound from human plasma. Proc Natl Acad Sci USA 88: 6259-6263, 1991.

4. Manunta P, Stella P, Rivera R, Ciurlino D, Cusi D, Ferrandi M, Hamlyn JM and Bianchi G: Left ventricular mass, stroke volume, and ouabain-like factor in essential hypertension. Hypertension 34: 450-456, 1999.

5. Manunta P, Hamilton BP and Hamlyn JM: Structure-activity relationships for the hypertensinogenic activity of ouabain Role of the sugar and lactone ring. Hypertension 37: 472-477, 2001.

6. Huang BS, Huang X, Harmsen E and Leenen FH: Chronic central versus peripheral ouabain, blood pressure and sympathetic activity in rats. Hypertension 23: 1087-1090, 1994.

7. Winnicka K, Bielawski K, Bielawska A and Surazyński A Antiproliferative activity of derivatives of ouabain, digoxin and proscillaridin A in human MCF-7 and MDA-MB-231 breast cancer cells. Biol Pharm Bull 31: 1131-1140, 2008.

8. Newman RA, Yang P, Pawlus AD and Block KI: Cardiac glycosides as novel cancer therapeutic agents. Mol Interv 8 : 36-49, 2008

9. Tailler M, Senovilla L, Lainey E, Thépot S, Métivier D, Sébert M, Baud V, Billot K, Fenaux P, Galluzzi L, et al: Antineoplastic activity of ouabain and pyrithione zinc in acute myeloid leukemia. Oncogene 31: 3536-3546, 2012.

10. Pezzani R, Rubin B, Redaelli M, Radu C, Barollo S, Cicala MV Salvà M, Mian C, Mucignat-Caretta $\mathrm{C}$, Simioni $\mathrm{P}$, et al: The antiproliferative effects of ouabain and everolimus on adrenocortical tumor cells. Endocr J 61: 41-53, 2014.

11. Brouillard F, Tondelier D, Edelman A and Baudouin-Legros M Drug resistance induced by ouabain via the stimulation of MDR 1 gene expression in human carcinomatous pulmonary cells. Cancer Res 61: 1693-1698, 2001.

12. Riganti C, Campia I, Polimeni M, Pescarmona G, Ghigo D and Bosia A: Digoxin and ouabain induce P-glycoprotein by activating calmodulin kinase II and hypoxia-inducible factor-1alpha in human colon cancer cells. Toxicol Appl Pharmacol 240: 385-392, 2009

13. Cordon-Cardo C, O'Brien JP, Boccia J, Casals D, Bertino JR and Melamed MR: Expression of the multidrug resistance gene product (P-glycoprotein) in human normal and tumor tissues. J Histochem Cytochem 38: 1277-1287, 1990.

14. De Visser KE, Eichten A and Coussens LM: Paradoxical roles of the immune system during cancer development. Nat Rev Cancer 6: 24-37, 2006.

15. Rodrigues-Mascarenhas S, Da Silva de Oliveira A, Amoedo ND Affonso-Mitidieri OR, Rumjanek FD and Rumjanek VM: Modulation of the immune system by ouabain. Ann N Y Acad Sci 1153, 153-163, 2009.

16. Honig SM, Fu S, Mao X, Yopp A, Gunn MD, Randolph GJ and Bromberg JS: FTY720 stimulates multidrug transporter- and cysteinyl leukotriene-dependent $\mathrm{T}$ cell chemotaxis to lymph nodes. J Clin Invest 111: 627-637, 2003.

17. Eisenbraun MD, Mosley RL, Teitelbaum DH and Miller RA Altered development of intestinal intraepithelial lymphocytes in P-glycoprotein-deficient mice. Dev Comp Immunol 24: 783-795, 2000.

18. Gupta S, Kim CH, Tsuruo T and Gollapudi S: Preferential expression and activity of multidrug resistance gene 1 product (P-glycoprotein), a functionally active efflux pump, in human CD8+ T cells: A role in cytotoxic effector function. J Clin Immunol 12: 451-458, 1992.

19. Raghu G, Park SW, Roninson IB and Mechetner EB: Monoclonal antibodies against P-glycoprotein, an MDR1 gene product, inhibit interleukin-2 release from PHA-activated lymphocytes. Exp Hematol 24: 1258-1264, 1996.

20. Valente RC, Capella LS, Nascimento CR, Braga F, Echevarria-Lima J, Lopes AG and Capella MAM: ABCB1 (P-glycoprotein) but not ABCC1 (MRP1) is downregulated in peripheral blood mononuclear cells of spontaneously hypertensive rats. Pflugers Arch 456: 359-368, 2008

21. Shapiro HM, Schildkraut ER, Curbelo R, Turner RB, Webb RH, Brown DC and Block MJ: Cytomat-R: A computer-controlled multiple laser source multiparameter flow cytophotometer system. J Histochem Cytochem 25: 836-844, 1977.

22. Hoffman RA, Kung PC, Hansen WP and Goldstein G: Simple and rapid measurement of human $\mathrm{T}$ lymphocytes and their subclasses in peripheral blood. Proc Natl Acad Sci USA 77: 4914-4917, 1980
23. Leite DF, Echevarria-Lima J, Salgado LT, Capella MA, Calixto JB and Rumjanek VM: In vivo and in vitro modulation of MDR molecules in murine thymocytes. Int Immunopharmacol 6: 204-215, 2006

24. Zhang J, Hamlyn JM, Karashima E, Raina H, Mauban JR, Izuka M, Berra-Romani R, Zulian A, Wier WG and Blaustein MP: Low-dose ouabain constricts small arteries from ouabain-hypertensive rats: Implications for sustained elevation of vascular resistance. Am J Physiol Heart Circ Physiol 297: H1140-H1150, 2009.

25. Nakanishi K: Basophils as APC in Th2 response in allergic inflammation and parasite infection. Curr Opin Immunol 22: 814-820, 2010.

26. Cromheecke JL, Nguyen KT and Huston DP: Emerging role of human basophil biology in health and disease. Curr Allergy Asthma Rep 14: 408, 2014

27. Cole SP: Targeting multidrug resistance protein 1 (MRP1, ABCC1): Past, present and future. Annu Rev Pharmacol Toxicol 54: 95-117, 2014.

28. Tacke F, Ginhoux F, Jakubzick C, van Rooijen N, Merad M and Randolph GJ: Immature monocytes acquire antigens from other cells in the bone marrow and present them to $\mathrm{T}$ cells after maturing in the periphery. J Exp Med 203: 583-597, 2006.

29. Schiff DE, Kline L, Soldau K, Lee JD, Pugin J, Tobias PS and Ulevitch RJ: Phagocytosis of gram-negative bacteria by a unique CD14-dependent mechanism. J Leukoc Biol 62: 786-794, 1997.

30. Akira S and Hemmi H: Recognition of pathogen-associated molecular patterns by TLR family. Immunol Lett 85: 85-95, 2003.

31. Ebner S, Hofer S, Nguyen VA, Fürhapter C, Herold M, Fritsch P, Heufler C and Romani N: A novel role for IL-3: Human monocytes cultured in the presence of IL-3 and IL-4 differentiate into dendritic cells that produce less IL-12 and shift Th cell responses toward a Th2 cytokine pattern. J Immunol 168: 6199-6207, 2002.

32. Tian J, Li X, Liang M, Liu L, Xie JX, Ye Q, Kometiani P, Tillekeratne M, Jin R and Xie Z: Changes in sodium pump expression dictate the effects of ouabain on cell growth. J Biol Chem 284: 14921-14929, 2009.

33. Schoner W and Scheiner-Bobis G: Endogenous and exogenous cardiac glycosides: Their roles in hypertension, salt metabolism and cell growth. Am J Physiol Cell Physiol 293: C509-C536, 2007.

34. De Rezende Corrêa G, Araujo dos Santos A, Frederico Leite Fontes $\mathrm{C}$ and Giestal de Araujo E: Ouabain induces an increase of retinal ganglion cell survival in vitro: The involvement of protein kinase C. Brain Res 1049: 89-94, 2005.

35. Valente RC, Nascimento CR, Araujo EG and Rumjanek VM: Mcd14 expression in human monocytes is downregulated by ouabain via transactivation of epithelial growth factor receptor and activation of p38 mitogen-activated protein kinase. Neuroimmunomodulation 16: 228-236, 2009.

36. Pires V, Harab RC, Olej B and Rumjanek VM: Ouabain effects on activated lymphocytes: Augmentation of CD25 expression on TPA-stimulated cells and of CD69 on PHA- end TPA-stimulated cells. Int J Immunopharmacol 19: 143-148, 1997.

37. Matsumori A, Ono K, Nishio R, Igata H, Shioi T, Matsui S, Furukawa Y, Iwasaki A, Nose Y and Sasayama S: Modulation of cytokine production and protection against lethal endotoxemia by the cardiac glycoside ouabain. Circulation 96: 1501-1506, 1997.

38. Foey AD, Crawford A and Hall ND: Modulation of cytokine production by human mononuclear cells following impairment of Na, K-ATPase activity. Biochim Biophys Acta 1355: 43-49, 1997.

39. de Vasconcelos DI, Leite JA, Carneiro LT, Piuvezam MR, de Lima MR, de Morais LC, Rumjanek VM and Rodrigues-Mascarenhas S: Anti-inflammatory and antinociceptive activity of ouabain in mice. Mediators Inflamm 2011: 912925, 2011.

40. De Paiva LS, Costa KM, Canto FB, Cabral VR, Fucs R, Nobrega A and Rumjanek VM: Modulation of mature B cells in mice following treatment with ouabain. Immunobiology 216 : 1038-1043, 2011

41. Echevarria-Lima J and Rumjanek VM: Effect of ouabain on the immune system. Curr Hypertens Rev 2: 83-95, 2006.

42. De Sá Lima L, Kawamoto EM, Munhoz CD, Kinoshita PF, Orellana AM, Curi R, Rossoni LV, Avellar MC and Scavone C: Ouabain activates NFKB through an NMDA signaling pathway in cultured cerebellar cells. Neuropharmacology 73: 327-336, 2013. 
43. Vairo G and Hamilton JA: Activation and proliferation signals in murine macrophages: Stimulation of $\mathrm{Na}+\mathrm{K}+-\mathrm{ATPase}$ activity by hemopoietic growth factors and other agents. J Cell Physiol 134: 13-24, 1988

44. Teixeira MP and Rumjanek VM: Ouabain affects the expression of activation markers, cytokine production and endocytosis of human monocytes. Mediators Inflamm 2014: 760368, 2014.

45. Wimazal F, Germing U, Kundi M, Noesslinger T, Blum S, Geissler P, Baumgartner C, Pfeilstoecker M, Valent P and Sperr WR: Evaluation of the prognostic significance of eosinophilia and basophilia in a larger cohort of patients with myelodysplastic syndromes. Cancer 116: 2372-2381, 2010.

46. Bishara S, Griffin M, Cargill A, Bali A, Gore ME, Kaye SB, Shepherd JH and Van Trappen PO: Pre-treatment white blood cell subtypes as prognostic indicators in ovarian cancer. Eur J Obstet Gynecol Reprod Biol 138: 71-75, 2008.
47. Delou JM, Lopes AG and Capella M: Unveiling the role of multidrug resistance proteins in hypertension. Hypertension 54: 210-216, 2009.

48. Dostanic I, Paul RJ, Lorenz JN, Theriault S, Van Huysse JW and Lingrel JB: The alpha2-isoform of Na-K-ATPase mediates ouabain-induced hypertension in mice and increased vascular contractility in vitro. Am J Physiol Heart Circ Physiol 288: H477-H485, 2005.

49. Ueda K, Okamura N, Hirai M, Tanigawara Y, Saeki T, Kioka N Komano T and Hori R: Human P-glycoprotein transports cortisol, aldosterone, and dexamethasone, but not progesterone. J Biol Chem 267: 24248-24252, 1992.

50. Van Helvoort A, Smith AJ, Sprong H, Fritzsche I, Schinkel AH, Borst P and Van Meer G: MDR1 P-glycoprotein is a lipid translocase of broad specificity, while MDR3 P-glycoprotein specifically translocates phosphatidylcholine. Cell 87: 507-517, 1996. 